Article

\title{
A Numerical Investigation on De-NOx Technology and Abnormal Combustion Control for a Hydrogen Engine with EGR System
}

\author{
Hao Guo ${ }^{D}$, Song Zhou *, Jiaxuan Zou and Majed Shreka \\ College of Energy and Power Engineering, Harbin Engineering University, Harbin 150001, China; \\ guohao618@hrbeu.edu.cn (H.G.); zou_jx@hrbeu.edu.cn (J.Z.); majed.shreka@outlook.com (M.S.) \\ * Correspondence: songzhou@hrbeu.edu.cn; Tel.: +86-138-4506-3167
}

Received: 30 August 2020; Accepted: 16 September 2020; Published: 17 September 2020

\begin{abstract}
The combustion emissions of the hydrogen-fueled engines are very clean, but the problems of abnormal combustion and high NOx emissions limit their applications. Nowadays hydrogen engines use exhaust gas recirculation (EGR) technology to control the intensity of premixed combustion and reduce the NOx emissions. This study aims at improving the abnormal combustion and decreasing the NOx emissions of the hydrogen engine by applying a three-dimensional (3D) computational fluid dynamics (CFD) model of a single-cylinder hydrogen-fueled engine equipped with an EGR system. The results indicated that peak in-cylinder pressure continuously increased with the increase of the ignition advance angle and was closer to the top dead center (TDC). In addition, the mixture was burned violently near the theoretical air-fuel ratio, and the combustion duration was shortened. Moreover, the NOx emissions, the average pressure, and the in-cylinder temperature decreased as the EGR ratio increased. Furthermore, increasing the EGR ratio led to an increase in the combustion duration and a decrease in the peak heat release rate. EGR system could delay the spontaneous combustion reaction of the end-gas and reduce the probability of knocking. The pressure rise rate was controlled and the in-cylinder hot spots were reduced by the EGR system, which could suppress the occurrence of the pre-ignition in the hydrogen engine.
\end{abstract}

Keywords: computational fluid dynamics; knocking; hydrogen engine; exhaust gas recirculation; pre-ignition

\section{Introduction}

In recent years, the number and application scale of internal combustion engines has increased dramatically, and the consequent shortage of petroleum resources has become an important issue facing the world [1,2]. It is estimated that by 2020 China's car ownership will reach 280 million vehicles, which could make China the largest country in terms of car ownership. Besides, the challenges facing gasoline vehicles have become even more acute [3,4], making the development of new energy vehicles crucial, especially, after the implementation of the new $\mathrm{CO}_{2}$ emission limit, which will make the demand for new energy sources more urgent.

Hydrogen energy can meet the requirements of the environment, the resources, and sustainable development based on its advantages of strong renewability, high environmental protection, clean and efficient combustion, and abundance in resources $[5,6]$. This is unmatched by other new energy sources. Therefore, hydrogen is the energy hope of humanity in the future. Hydrogen is considered as the cleanest fuel for internal combustion engines [7]. This is because hydrogen combustion produces only water and a small amount of nitrogen oxides without carbon deposits and particles, hence, greatly reducing engine wear and lubricant contamination [8,9]. Vigorously developing hydrogen 
energy could alleviate the contradiction between fuel supply and demand and reduce exhaust gas emissions [10]. At present, the Chinese government has listed hydrogen energy as one of the key development directions of the national medium and long-term energy strategic plan for 2025.

Due to the extremely small density of hydrogen, the injection of a large amount of it inevitably reduces the charging efficiency of the internal combustion engine, which makes the theoretical power of the port injection hydrogen engine $15 \%$ lower than that of the same type of gasoline engine. The combustion temperature of the hydrogen-fueled engine increases sharply with the increase of the equivalent fuel/air ratio enhancing the formation of nitrogen oxides [11]. Therefore, hydrogen-fueled engines usually operate in lean-burn conditions to control the NOx emissions, which in turn cause the performance parameters to drop. The NOx emissions of the hydrogen-fueled engine change significantly with the change of fuel/air equivalence ratio. How to improve the power density of hydrogen-fueled engines without increasing the NOx emissions is a problem that researchers are trying to solve.

Exhaust gas recirculation (EGR) is the most effective means for traditional internal combustion engines to reduce NOx emissions. Some scholars have also studied the possibility of using the EGR system with the hydrogen engine to reduce NOx emissions. Heffel [12] converted a 2.0 L gasoline engine into a hydrogen-fueled engine with an intercooler for the EGR system. After the stoichiometric operation, the NOx emissions after the three-way catalytic converter were very low.

Low-temperature combustion (LTC) technology has been widely used in diesel engines in recent years. This technology uses EGR system and injection parameter adjustment to control the intensity of premixed combustion, reduce the in-cylinder temperature, and avoid the NOx generation region [13]. Controlling NOx emissions from hydrogen-fueled engines can be achieved by means of LTC technology using delayed ignition angles, lean burns, and EGR. Controlling the hydrogen injection amount and the EGR system increases the specific heat capacity of the gas in the cylinder and slows down the combustion rate, which in turn reduces the combustion temperature and, thus, the NOx emissions [14,15]. In addition, if the EGR post-gas mixture reaches a stoichiometric ratio, a three-way catalytic converter could be used to reduce the NOx emissions. Therefore, the hydrogen-fueled engine can burn a higher concentration of the mixed gas after EGR, thereby increasing the output of torque and power.

Subramanian [16] found that delaying the spark timing in the hydrogen-fueled engines could reduce NOx emissions but the decrease in the thermal efficiency could not be avoided especially in high-speed and heavy-load conditions. Delaying the spark timing decreased the output power and the torque of the internal combustion engine and its effect on reducing NOx emissions was also very limited. In addition, lean burn can achieve very low NOx emissions, but it is difficult to meet the requirements of higher power output.

Sierens [17] compared the lean burn and EGR operations on an EGR engine at $600 \mathrm{r} / \mathrm{min}$. The results showed that EGR reduced pumping losses at low loads, which increased the efficiency and decreased NOx emissions to $30 \%$. Besides, the cooling temperature in EGR from $20{ }^{\circ} \mathrm{C}$ to $40{ }^{\circ} \mathrm{C}$ did not have much effect on NOx emissions. Nande [18] studied the effect of the EGR ratio on combustion and emissions characteristics of a hydrogen engine. Test results showed that increasing the EGR ratio slowed down the burning rate. In addition, the NOx emissions decreased from $4000 \mathrm{ppm}$ to $100 \mathrm{ppm}$ with the rising EGR ratio from $0 \%$ to $35 \%$.

Safari [19] used a thermodynamic model calculation to study the method of reducing NOx formation in the hydrogen-fueled engine and compared the effects of cold EGR and hot EGR. He found that both cold and hot EGR could effectively reduce the NOx emissions formation, but the thermal EGR effect was better. However, these studies did not form a systematic control strategy. Yang et al. [20,21] found that, attributed to higher in-cylinder temperature, the NO emission has an obvious increase by using dual injection modes (especially, using spaced dual injection). The NO emission under the equivalent ratio of 0.67 was more than that under the equivalent ratio of 0.5 . 
Lee et al. [22] studied the high power performance with zero NOx emission in a hydrogen-fueled spark-ignition engine by lean boosting and valve timing. Luo et al. [23] analyzed inducing factors and frequency of combustion knock in hydrogen-fueled engines. The results showed that ignition timing and backfire were the two important factors contributing to generate combustion knock at high engine speed in a port fuel injection (PFI) engine.

In addition, although the hydrogen-fueled engine burns fuel faster than the gasoline engine, it has a wide ignition limit, achieves lean combustion easily, and further reduces the harmful exhaust gas emissions [24]. Nevertheless, the abnormal combustion in the hydrogen-fueled engine is likely to occur when the combustion condition is not proper [25]. When pre-ignition occurs, the engine is running rough, the body is prone to overheat, the engine's thermal and mechanical loads are aggravated, and the wear is increased, decreasing its service life. Pre-ignition also produces a variety of noise and causes piston piercing. Continued advance to early combustion induces deflagration and tempering, which will cause the hydrogen-fueled engine to stop working in severe cases.

Abnormal combustion of hydrogen-fueled engines has become a major problem that limits its utility [26]. At present, computational fluid dynamics (CFD) has developed rapidly [27,28]. It has become a reality to study the flow field characteristics, combustion characteristics, and abnormal combustion inside the cylinders of the hydrogen-fueled engines using high-performance computer simulation technology [29].

Nowadays, hydrogen engines can use EGR technology to control the intensity of premixed combustion and reduce the NOx emissions. This study aims at improving the abnormal combustion and decreasing the NOx emissions of the hydrogen engine by applying a three-dimensional (3D) CFD model of a single-cylinder hydrogen-fueled engine equipped with an EGR system (Section 2). In addition, the combustion strategy and EGR strategy for the combustion characteristics of a hydrogen-fueled engine were studied (Section 3). Moreover, the relationship between the pressure increase rate of the hydrogen-fueled engine and the pre-ignition at different EGR ratios was analyzed (Section 3). Finally, measures to suppress the abnormal combustion of the hydrogen-fueled engine were proposed.

\section{Methods and Model}

\subsection{Governing Equations}

The governing equations of the hydrogen-fueled engine simulation process include the energy conservation equation, mass conservation equation, momentum conservation equation, component conservation equation, state equation of gas mixture, and turbulence model equation. The law of conservation of mass: the mass flowing into the unit is equal to the mass flowing out of the unit at the same time. $u, v$, and $w$ represent the component of the velocity vector in the $x, y$, and $z$ direction.

$$
\begin{gathered}
\frac{\partial \rho}{\partial t}+\operatorname{div}(\rho \vec{u})=S_{m} \\
\operatorname{div}(\rho \vec{u})=\frac{\partial(\rho u)}{\partial x}+\frac{\partial(\rho v)}{\partial y}+\frac{\partial(\rho w)}{\partial z}
\end{gathered}
$$

where $\rho$ denotes the density; $t$ is the time; $S m$ is the source item; $\vec{u}$ indicates the speed vector; $u, v, w$ are the component of the velocity vector in the $x, y, z$ direction.

Momentum conservation law: for the same fluid, the momentum change rate of the entire system is equal to the sum of all external forces acting on it.

$$
\frac{\partial \rho u_{i}}{\partial t}+\frac{\partial \rho u_{i} u_{j}}{\partial x_{j}}=-\frac{\partial P}{\partial x_{i}}+\frac{\partial \sigma_{i j}}{\partial x_{j}}+\rho g_{i}+F_{i}
$$




$$
\sigma_{i j}=\mu\left[\frac{\partial u_{i}}{\partial x_{j}}+\frac{\partial u_{j}}{\partial x_{i}}\right]-\frac{2}{3} \mu \frac{\partial u_{k}}{\partial x_{k}} \delta_{i j}
$$

where $P$ denotes the static pressure; $\sigma_{i j}$ is the viscous stress tensor; $\mu$ is the dynamic viscosity; $g_{i}$ is the gravity acceleration in the $i$ direction; $F_{i}$ refers to the external volume force.

The law of conservation of energy: the energy in the fluid per unit is the sum of the heat flow and the external force work.

$$
\frac{\partial \rho e}{\partial t}+\frac{\partial u_{j} \rho e}{\partial x_{j}}=-P \frac{\partial u_{j}}{\partial x_{j}}+\sigma_{i j} \frac{\partial u_{i}}{\partial x_{j}}+\frac{\partial}{\partial x_{j}}\left[K \frac{\partial T}{\partial x_{j}}\right]+\frac{\partial}{\partial x_{j}}\left[\rho D \sum_{m} h_{m} \frac{\partial Y_{m}}{\partial x_{j}}\right]+S_{h}
$$

where $Y_{m}$ represents the mass fraction of component $\mathrm{m} ; D$ is the diffusion coefficient; $e$ denotes the specific internal energy; $K$ is the thermal conductivity; $h_{m}$ refers to the specific enthalpy; and $\sigma_{i j}$ is the stress tensor.

The model uses a standard model to simulate the gas flow in hydrogen engine. In the standard model, the enthalpy flow energy $(k)$ and the turbulent dissipation rate $(\varepsilon)$ are expressed as follows:

$$
\begin{gathered}
\frac{\partial \rho k}{\partial t}+\frac{\partial \rho u_{i} k}{\partial x_{i}}=\sigma_{i j} \frac{\partial u_{i}}{\partial x_{j}}+\frac{\partial}{\partial x_{j}} \frac{\mu}{\operatorname{Pr}_{t k e}} \frac{\partial k}{\partial x_{j}}-\rho \varepsilon+S \\
\sigma_{i j}=2 \mu_{t} S_{i j}-\frac{2}{3} \delta_{i j}\left[\rho k+\mu_{t} \frac{\partial u_{i}}{\partial x_{i}}\right], \mu_{t}=C_{\mu} \rho \frac{k^{2}}{\varepsilon} \\
\frac{\partial \rho \varepsilon}{\partial t}+\frac{\partial\left(\rho u_{i} \varepsilon\right)}{\partial x_{i}}=\frac{\partial}{\partial x_{j}}\left[\frac{\mu}{\operatorname{Pr}_{\varepsilon}} \frac{\partial \varepsilon}{\partial x_{j}}\right]-c_{\varepsilon 3} \rho \varepsilon \frac{\partial u_{i}}{\partial x_{i}}+\left[c_{\varepsilon 1} \frac{\partial u_{i}}{\partial x_{j}} \sigma_{i j}-c_{\varepsilon 2} \rho \varepsilon+c_{s} S_{s}\right] \frac{\varepsilon}{k}-\rho R
\end{gathered}
$$

where $\sigma_{i j}$ indicates the stress tensor; $\mu_{t}$ represents the turbulent viscosity; $c_{\varepsilon 1}, c_{\varepsilon 2}, c_{\varepsilon 3}$ are the empirical constant; $S_{S}$ is the source item; $\operatorname{Pr}$ is the Prandtl number.

The fuel is thoroughly mixed with air to form a homogeneous mixture before the start of combustion. Normally, the gas in front of the flame front rapidly approaches the combustion state, and the mixture after the flame front is usually unburned, which means that the combustion system contains two stable states. The turbulent flame propagation equation used in the simulation software is described as follows:

$$
s_{t}=s_{l}+u^{\prime}\left\{-\frac{a_{4} b_{3}^{2}}{2 b_{1}} D a+\left[\left(\frac{a_{4} b_{3}^{2}}{2 b_{1}} D a\right)^{2}+a_{4} b_{3}^{2} D a\right]^{1 / 2}\right\}
$$

where $u^{\prime}$ denotes the turbulent velocity; $S_{1}$ represents the turbulent velocity; $a_{4}, b_{1}, b_{3}$ are the empirical constant; $D a$ is the Damocles number.

\subsection{Engine Dimensions and CFD Model}

The hydrogen-fueled engine was modified from the K5A gasoline engine produced by Mitsubishi Heavy Industries, Japan. The hydrogen engine was horizontally placed and water-cooled in a single cylinder. Besides, the engine can change the compression ratio by changing the height of the cylinder head. The hydrogen was injected from the inlet port fuel injection. The hydrogen injection pressure was $0.2 \mathrm{MPa}$. Furthermore, the mixed gas was formed by the inlet premixing method. The K5A hydrogen engine air/fuel ratio $(\lambda)$ varied from 1.05 to 2.04 and the EGR ratio ranged from 0 to $20 \%$. The basic parameters of a hydrogen-fueled engine are listed in Table 1. 
Table 1. K5A hydrogen engine dimensions.

\begin{tabular}{cc}
\hline Parameter & Value \\
\hline Bore & $85 \mathrm{~mm}$ \\
Stroke & $85 \mathrm{~mm}$ \\
Compression Ratio & 6.8 \\
Cylinder Number & 1 \\
Speed & $2000 \mathrm{r} / \mathrm{min}$ \\
Capacity & $0.482 \mathrm{~L}$ \\
\hline
\end{tabular}

The CFD model of a hydrogen engine uses computer-aided design (CAD) software and AVL-Fire is selected as the CFD simulation software. Figure 1 shows the K5A 3D model and the computational mesh grids with a maximum number of moving mesh grids of approximately 682,143 . The crank angle was used as the simulation case step, and the step when the piston reached TDC was defined as $0^{\circ} \mathrm{CA}$. The simulation was started from the closing of the intake valve at $-117^{\circ} \mathrm{CA}$ before the top dead center (bTDC) and ended at the closing of the exhaust valve at $157^{\circ} \mathrm{CA}$ after the top dead center (aTDC). The in-cylinder flow at the beginning of the simulation defined by using empirical formulas based on engine speed, piston speed, and valve lift. In addition, the turbulence model was selected based on the working characteristics of the hydrogen-fueled internal combustion engines, while the combustion model was the coherent flame model, which is suitable for the premixed combustion. Besides, the Zeldovich model and the AnB Knock model were used as the NOx generation model and the knock-on model, respectively.

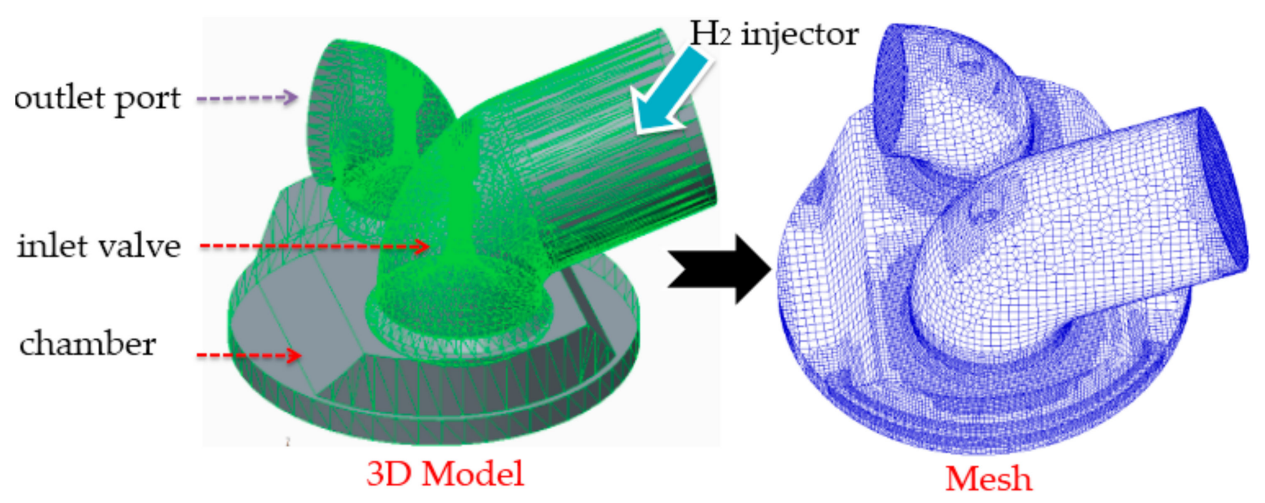

Figure 1. Computational fluid dynamics (CFD) model of a hydrogen engine.

The experiment data of K5A hydrogen engine was under $100 \%$ load without EGR. The atmospheric pressure was $101.08 \mathrm{kPa}$ and the initial air temperature was $304 \mathrm{~K}$. Besides, the engine intake air temperature, the cooling water temperature, the intake air humidity, and the relative humidity of intake air were $305.2 \mathrm{~K}, 348 \mathrm{~K}, 22.52 \mathrm{~g} / \mathrm{kg}$, and $78.7 \%$, respectively. Moreover, the gas used in the experiment contained $99.8 \%$ hydrogen and $0.2 \%$ other gases $\left(\mathrm{N}_{2}, \mathrm{CH}_{4}, \mathrm{CO}, \mathrm{H}_{2} \mathrm{O}\right.$, etc.). CFD model used the same initial condition settings as the experiment data. As shown in Figure 2, the simulated pressure and the measured pressure at each crank angle are in good agreement. The maximum relative error of the peak pressure is about $4.8 \%$, which satisfies the requirements of simulation calculation accuracy. It was verified that the calculation model can accurately reflect the actual combustion process of the K5A hydrogen-fueled engine, and the simulation data can provide guidance for the research on the hydrogen engine. 


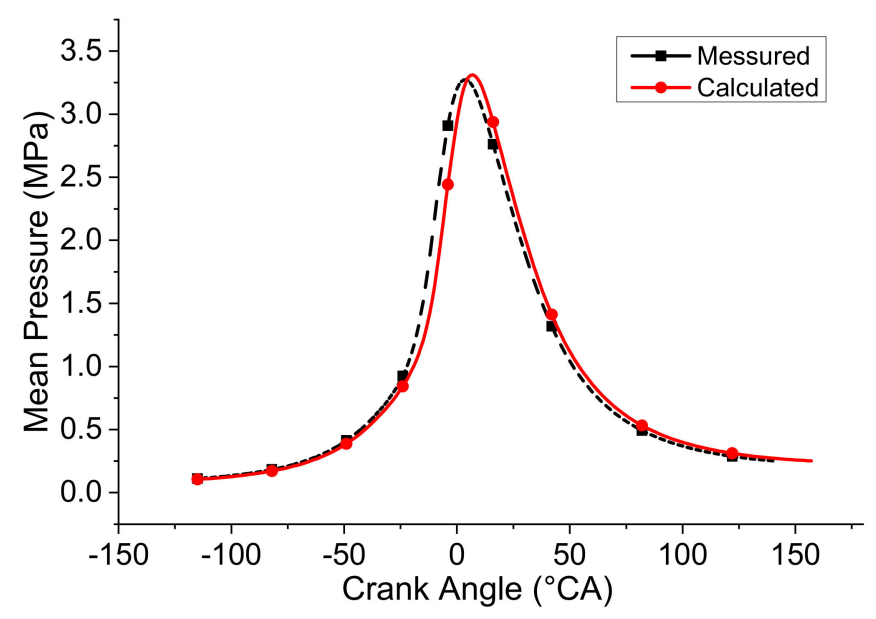

Figure 2. Data comparisons to a hydrogen engine

\section{Results and Discussions}

\subsection{Factors Influencing the Performance and Emissions}

The spark timing has a very important influence on the performance of a hydrogen engine. To obtain good in-cylinder combustion characteristics for K5A hydrogen-fueled engine and, thus, get better economy, power, and emissions, it is necessary to determine a reasonable spark timing. The effect of spark timing on the combustion process of a hydrogen-fueled engine was verified by setting the spark advance angle to $5^{\circ} \mathrm{CA}, 10^{\circ} \mathrm{CA}, 15^{\circ} \mathrm{CA}$, respectively, without considering the use of external an EGR system. The in-cylinder pressure corresponding to different spark advance angles at $2000 \mathrm{r} / \mathrm{min}$ engine speed and air/fuel ratio $\lambda=1.47$ is shown in Figure 3.

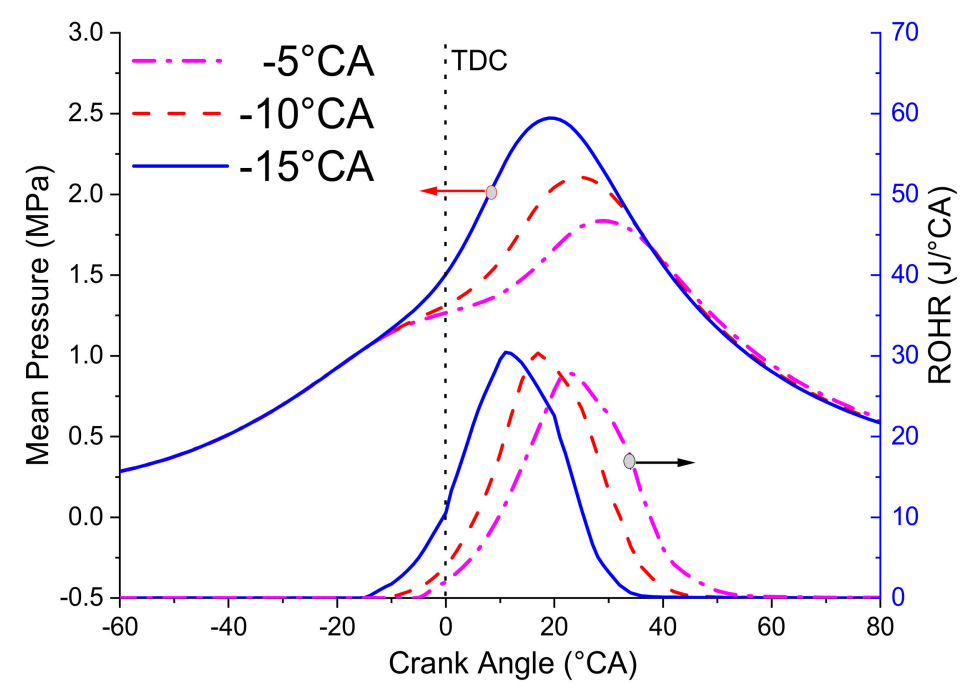

Figure 3. Pressure and heat release rate at different spark timings.

It can be seen from Figure 3 that earlier spark timing increases the slope of the average cylinder pressure curve and leads to more severe combustion of the hydrogen-air mixture. If combustion is progressively advanced before TDC, the work from the piston to cylinder mixture during the engine compression stroke increases. On the other hand, if the spark timing is retarded, the peak pressure appears later in the power stroke, and its peak value decreases. As a consequence, useful output during power stroke is reduced. Normally, the spark advance angle is optimized to give the hydrogen engine maximum brake torque (MBT). However, excessive ignition advance increases the compression negative work, the knocking tendency, and the thermal load of the cylinder. Therefore, looking for an optimal spark advance is the key to improve the performance of a hydrogen-fueled engine. 
From the rate of heat release (ROHR) in Figure 3, when the spark timing is $-15^{\circ} \mathrm{CA} b T D C$, the in-cylinder heat release rate reaches its maximum peak at $11^{\circ} \mathrm{CA}$ aTDC. The combustion rate of the hydrogen-air mixture is extremely fast, and the mixture gas is combusted sufficiently after spark. As the core of the flame propagates, the in-cylinder pressure begins to rise sharply. The in-cylinder mixture near TDC is almost fully mixed due to the rapid diffusion of hydrogen and the mixture can burn rapidly under the combined action of airflow and high temperature so the average cylinder pressure increases quickly. The slope of the in-cylinder pressure represents the rate of pressure increase, which increases with the increase of the spark advance angle increases. In addition, the earlier the spark timing is, the larger the peak combustion heat release rate is, and the shorter the combustion duration is. As the spark advance angle increases, the overall heat release process of combustion becomes closer to the TDC, which makes combustion closer to constant volume.

As can be seen from Figure 4a, the average in-cylinder temperature continues to increase as the spark advance angle increases. The earlier the spark timing, the lower the average temperature in the cylinder when the exhaust valve opens. This is because the peak temperature is higher when the ignition is earlier, the heat loss of heat transfer is also greater, and more energy is converted in the power stroke. Besides, the average in-cylinder temperature reaches $850 \mathrm{~K}$ at the end of the compression stroke, which creates conditions for the rapid propagation of the flame. After the spark plug ignites the mixture, the average temperature in the cylinder begins to rise sharply due to the extremely fast burning speed of hydrogen. Thereafter, as the fuel in the cylinder continues to burn rapidly, the highest average in-cylinder temperature reaches $2522 \mathrm{~K}$ at $27^{\circ} \mathrm{CA}$ aTDC.

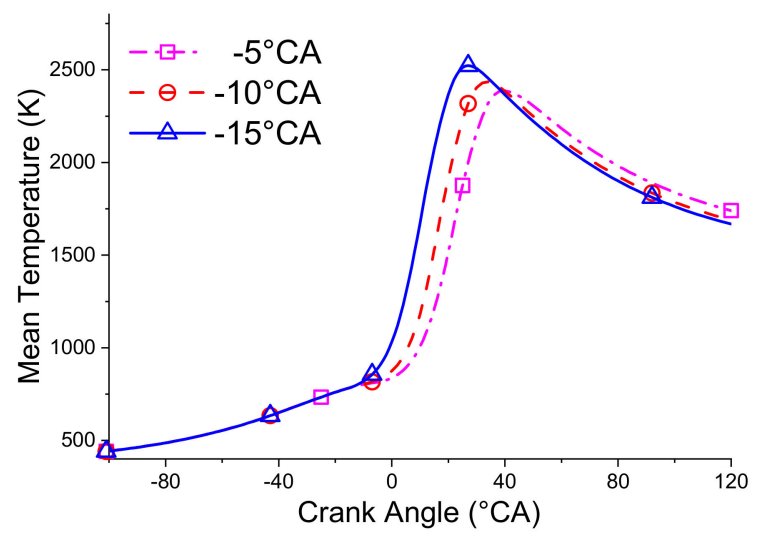

(a)

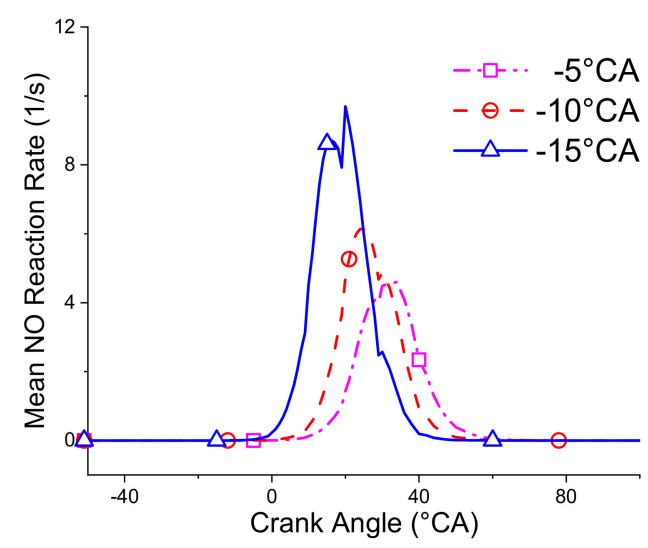

(b)

Figure 4. Average temperature and NO production rate at different spark timings: (a) average temperature; (b) NO generation rate.

At the TDC position, the combustion volume is the smallest, and the in-cylinder temperature and pressure are both very high. Besides, the peak average temperature of the simulated hydrogen engine in Figure $4 \mathrm{a}$ is about $2500 \mathrm{~K}$, which is much higher than the gasoline engine under the same conditions. Therefore, NOx emissions of the K5A hydrogen-fueled engine are more likely to occur. As shown in Figure $4 \mathrm{~b}$, when the spark advance is $15^{\circ} \mathrm{CA}$, the combustion heat release rate and the in-cylinder temperature both reach the peak value near $23^{\circ} \mathrm{CA}$ aTDC, which shows the same peak trend and close relationship. Although the oxygen content in-cylinder decreases due to combustion, the NO emission caused by high temperature is more obvious. In addition, it can be seen from the area enclosed by the $\mathrm{NO}$ reaction rate curve and the $\mathrm{X}$ coordinate axis that the total $\mathrm{NO}$ emission increases as the spark advance angle increases. The premixed combustion enhances the power of the hydrogen engine by using early injection but at the same time brings about the problem of rising NOx emissions during the compression stroke. 
The air/fuel ratio has a great influence on the performance of the hydrogen-fueled engine. Three different air/fuel ratios including 1.05, 1.47, and 2.04 were set to verify the impact of the air/fuel ratio on the hydrogen-fueled engine. Figure 5 shows the in-cylinder pressure under different equivalence ratios at $1100 \mathrm{r} / \mathrm{min}$ engine speed and $-30^{\circ} \mathrm{CA}$ ignition timing. At an air/fuel ratio of 2.04, the mixture gas is lean and the maximum pressure is limited, while at an air/fuel ratio of 1.47, the combustion heat release rate is 1.4 times higher than the former, indicating that the air/fuel ratio has a significant impact on the combustion pressure of the hydrogen-fueled engine. As the air/fuel ratio of the mixture approaches the theoretical air/fuel ratio $(\lambda=1)$, more combustible mixture combustion becomes exothermic, resulting in an increase in the pressure increase rate of the hydrogen-fueled engine. It can be seen from the heat release rate curve that as the air/fuel ratio approaches 1 , the combustible mixture becomes rich and the combustion speed increases. Besides, the combustion duration shortens, and the combustion heat release rate increases. Moreover, the combustion heat release rate curve is approximately normal and has a uniform variation which is different from gasoline fuel. However, due to the extremely fast burning rate of hydrogen, the detonation tendency increases after the equivalence ratio increases, and the abnormal combustion is more likely to occur.

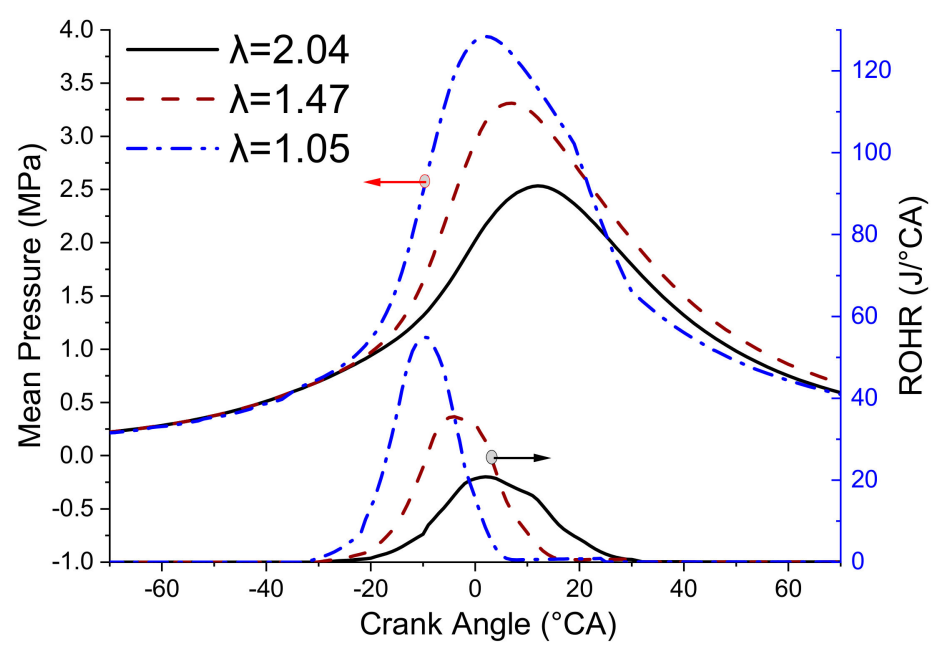

Figure 5. Different equivalent ratios of pressure and heat release rate.

From Figure 6, it can be seen that the emission of NO decreases with the increase of the air/fuel ratio. In lean combustion mode, the hydrogen-fueled engine can achieve a very low NO emission, which greatly reduces the $\mathrm{NO}$ emission of the hydrogen-fueled engine, indicating the research direction. At a lower air/fuel ratio, the mixture burns violently, and the high in-cylinder temperature and pressure promote the formation of a large amount of NO. As a result, the optimized ignition timing, the lean-burn technology, the proper EGR ratio, and the low-temperature combustion are the main factors to reduce the NOx emission from the hydrogen-fueled engine. 


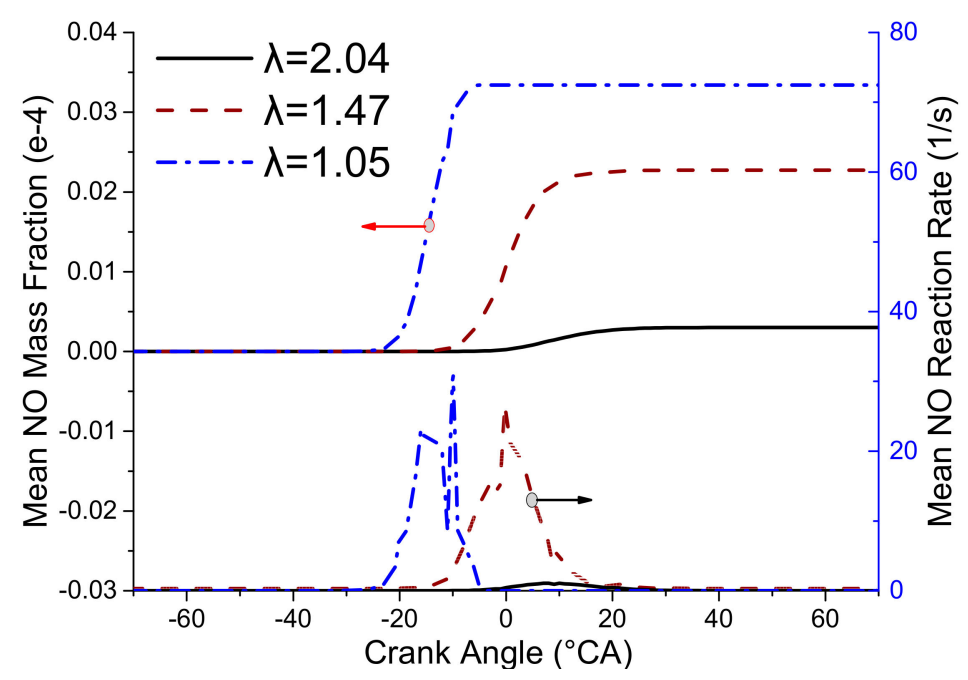

Figure 6. Different equivalent ratios of the mass fraction and NO reaction rate.

\subsection{Effects of External EGR System on Performance and Emissions}

The external EGR strategy greatly influences the low-temperature combustion mode of the hydrogen-fueled engine. Therefore, the effect of the external EGR ratio on the combustion process of the hydrogen engine was investigated using four different EGR ratios, that is, $1 \%, 10 \%, 15 \%$, and $20 \%$, at 2000r/min engine speed and an air/fuel ratio of 1.47. The in-cylinder pressure and temperature curves corresponding to different EGR ratios are shown in Figure 7.

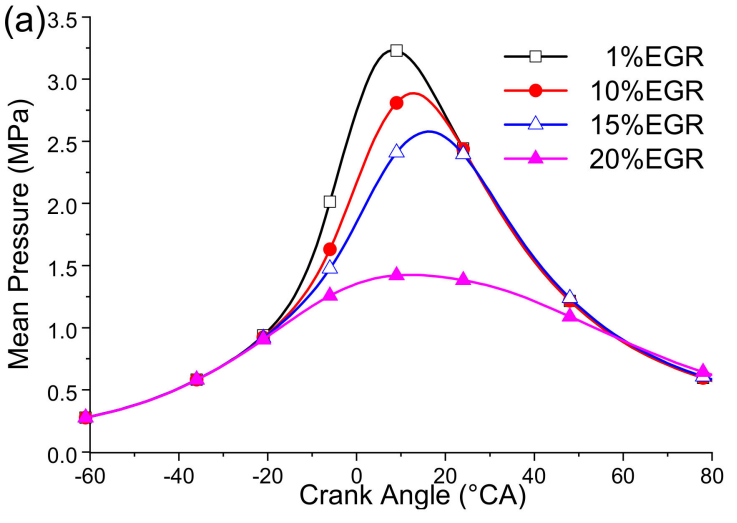

(a)

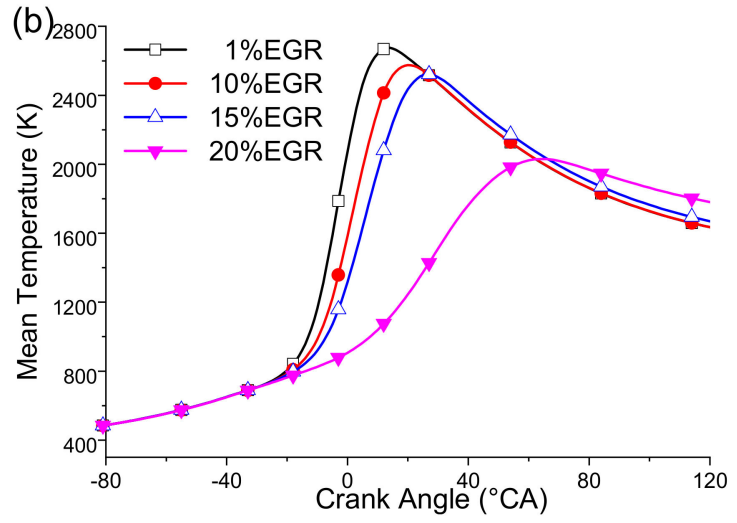

(b)

Figure 7. Mean in-cylinder pressure and temperature at different exhaust gas recirculation (EGR) ratios: (a) Mean in-cylinder pressure; (b) Mean in-cylinder temperature.

From Figure 7a, increasing the EGR ratio decreases the peak in-cylinder combustion pressure of the hydrogen-fueled engine. When the EGR ratio reaches $20 \%$, the in-cylinder pressure reduction effect is obvious. By considering the dynamics properties of the hydrogen-fueled engine, a higher EGR ratio could be used under low load, but an excessive EGR ratio should not be used under medium and high load. At different EGR ratios, the ignition delay is severely changed due to the dilution of the oxygen concentration and the change in the fresh charge. As shown in Figure $7 b$, as the EGR ratio increases, the temperature increase rate slows down and the temperature peak decreases and moves back. EGR suppresses the intense tendency of combustion to make the combustion flat, but $20 \%$ EGR ratio nearly interrupts the engine's normal combustion. In addition, the hydrogen combustion flame speed is very fast but easy to extinguish; hence, an excessive EGR ratio cannot be used. A large EGR ratio worsens the combustion in the $\mathrm{K} 5 \mathrm{~A}$ engine, which may lead to insufficient power output. 
Since the diffusion speed of hydrogen is extremely fast after the intake manifold is injected, the mixed hydrogen-oxygen gas could be quickly formed, and the premixed combustion is performed. Therefore, the hydrogen-fueled engine does not have the double-peak exothermic curve as the diesel engine. Figure $8 \mathrm{a}$ displays the heat release rate of a K5A hydrogen-fueled engine under four different EGR ratios. At a 1\% EGR ratio, the peak in-cylinder heat release rate is $153.4 \%$ higher than that at $20 \%$ EGR, and the combustion start angle is advanced by nearly $24^{\circ} \mathrm{CA}$. When the EGR ratio reaches $20 \%$, the combustion duration increases significantly, and the end of combustion appears later. Meanwhile, the larger the EGR ratio is, the longer the combustion duration is, and the lower the peak heat release rate is. This is because as the EGR ratio increases, the specific heat capacity of mixture in the cylinder increases and the oxygen concentration in the mixture greatly reduces. The exhaust gas circulated through the inlet port contains a large number of combustion emissions such as $\mathrm{NOx}, \mathrm{H}_{2} \mathrm{O}$, and $\mathrm{CO}_{2}$, which slows down the fuel mixture oxidation process. Under the joint effects of the above-mentioned factors, the mixture ignition delay is extended.

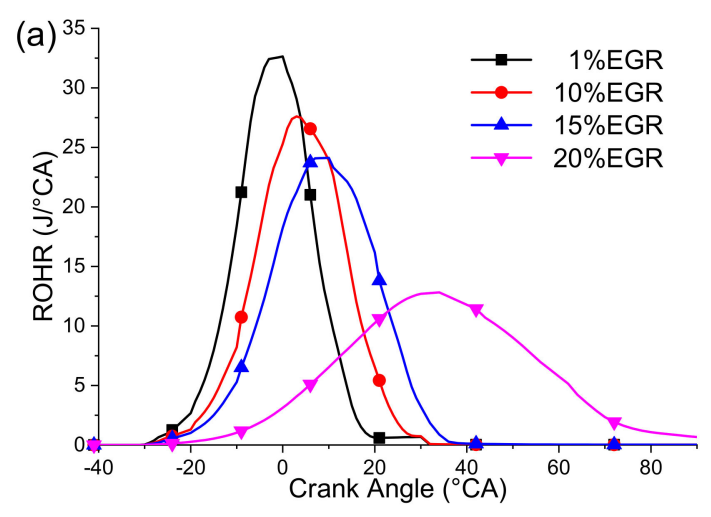

(a)

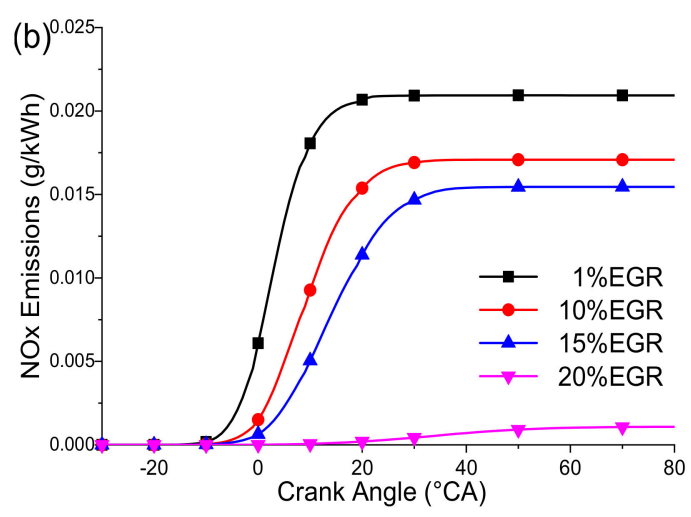

(b)

Figure 8. Rate of heat release (ROHR) and NOx emissions at different EGR ratios: (a) ROHR; (b) NOx emissions.

As shown in Figure $8 b$, as the EGR ratio increases, the mass fractions of NOx emissions significantly decrease. The reduction effect is very obvious when the EGR ratio is $20 \%$. The reduction of high-temperature zones and oxygen concentration are the main reasons for the decrease of NOx emissions by using EGR in a hydrogen engine. On the one hand, the lower oxygen concentration in the mixture and the in-cylinder temperature are sufficient to obtain a very low NOx emission. On the other hand, a large EGR ratio deteriorates the combustion, the economy of fuel, and the thermal efficiency of a hydrogen-fueled engine, which means that increasing the EGR ratio has certain limitations. Moreover, NO starts to form at $-10^{\circ} \mathrm{CA}$ bTDC and increases with the increase of the crank angle to reach its maximum value at $29^{\circ} \mathrm{CA}$ aTDC, and after that, it stays stable. After the ignition of the hydrogen-fueled engine, the flame rapidly propagates and the in-cylinder temperature sharply rises; thereby, the conditions for rapid NO formation are completely provided, and thus, a large amount of $\mathrm{NO}$ is formed after the flame front. As the EGR ratio increases, the NO generation rate decreases and the final production amount of NO decreases significantly. Most of NOx emissions are formed from $-10^{\circ} \mathrm{CA}$ to $29^{\circ} \mathrm{CA}$.

Using a high-ratio EGR strategy to reduce the concentration of oxygen at the inlet port can effectively control the premixed combustion temperature and achieve in-cylinder low-temperature combustion. This is helpful to suppress the generation of NOx emissions from the hydrogen engine and at the same time to delay the premature combustion phase caused by the early injection, hence, improving the combustion efficiency and the economics of hydrogen engines. 


\subsection{Controlling the Knocking by EGR System}

As the EGR ratio increases, the average phase of the curve moves toward the TDC during the compression stroke. As shown in Figure 9, as the EGR ratio of the hydrogen-fueled engine increases, the peak in-cylinder pressure rise rate continues to decrease and the average phase of the curve moves toward the TDC during the compression stroke and closer to the trend of the pure compression curve. Besides, the correlation between the maximum pressure rise rate and its corresponding crank angle is reduced, and the insufficient combustion at a large EGR ratio eventually leads to partial misfire. At a $15 \%$ EGR ratio, the maximum pressure increase rate is $0.069 \mathrm{MPa} /{ }^{\circ} \mathrm{CA}$, which is $46.7 \%$ lower than that of the engine without EGR.

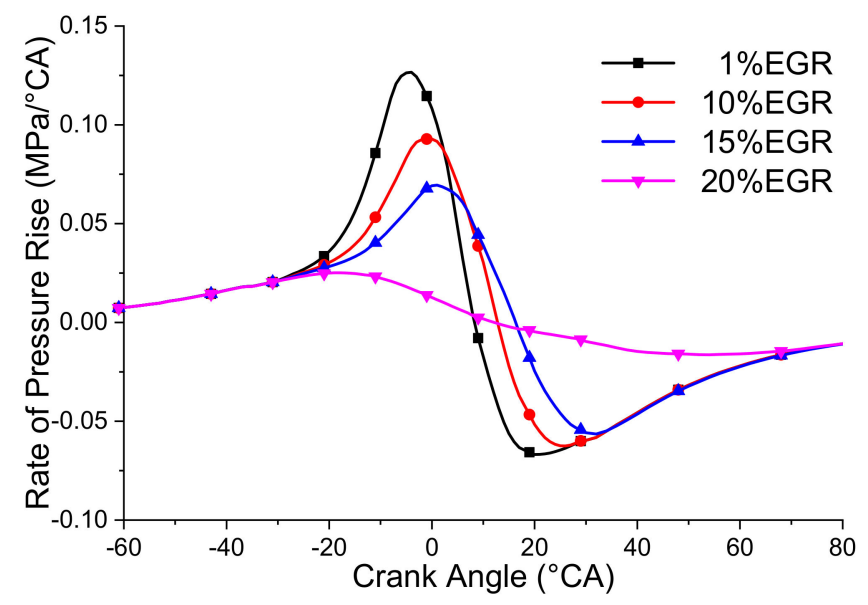

Figure 9. Influence of the EGR ratio on pressure increase rate.

Figure 10 shows the distribution cloud diagram of the in-cylinder combustion progress for two different EGR ratios, while the hydrogen engine speed was $2000 \mathrm{rpm}$ and the ignition timing $-20^{\circ} \mathrm{CA}$ bTDC $(\lambda=1.47)$. From Figure 10, the red color represents the burned area, while the blue color represents the unburned area. The area of the in-cylinder burned area at a 10\% EGR ratio is bigger than that of the burned area at a 20\% EGR ratio, and the flame travel distance is farther. It is obvious from the simulation results that the flame propagation speed decreases at a large EGR ratio. This is because as the EGR ratio increases, the oxygen concentration in the mixture becomes lower and the proportion of the inert gases such as $\mathrm{N}_{2}$ and $\mathrm{CO}_{2}$ increases, hence, reducing the ratio of combustion reactions.
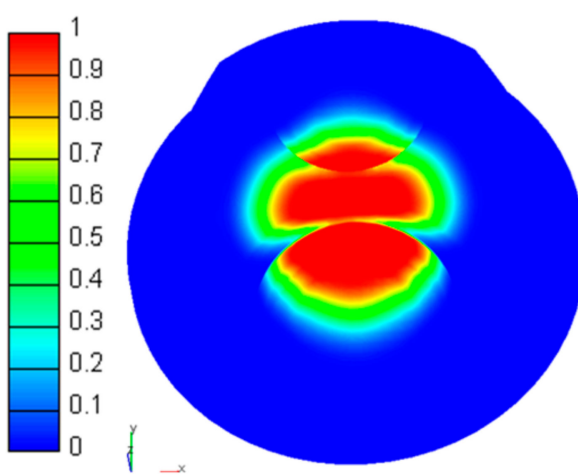

(a)

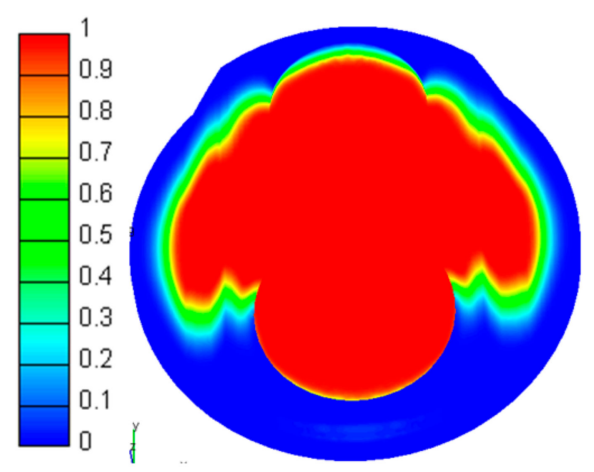

(b)

Figure 10. Combustion reaction progress variable at $10^{\circ} \mathrm{CA}$ after the top dead center (aTDC): (a) $20 \%$ EGR; (b) 10\% EGR.

By using the EGR system, the average in-cylinder combustion temperature is reduced and the possibility of tempering in the inlet port could be reduced before spark timing. However, at a high EGR 
ratio, the combustion temperature cannot reach too low a value, which decreases the flame propagation speed and prolong the combustion duration. The hydrogen engine cycle fluctuation becomes larger, and the combustion stability deteriorates. Therefore, precise control of the EGR ratio and fuel injection amount is required in order to fully utilize the role of low-temperature combustion technology in the hydrogen-fueled engine.

As shown in Figure 11, the reaction rate decreases with the increase of the EGR ratio, as can be seen from the comparison of reaction rates at the same distance of flame propagation. The red circle shows the reaction rate of the mixture at the end-gas of the original engine at $1 \%$ EGR ratio where there is a tendency of spontaneous combustion. The low-temperature combustion technology is used to control the injection while increasing the EGR ratio to $10 \%$. Under this engine working condition, the spontaneous combustion tendency of the end-gas mixture is mostly lost. Using EGR technology can effectively control the intensity of the premixed combustion of the hydrogen engine. At the same time, with the use of EGR cooler technology, the inert gas in the exhaust gas is used to dilute the mixture, reduce the molar concentration of oxygen, and lower the temperature of end-gas. In the end, the spontaneous combustion tendency of end-gas is effectively suppressed, and knocking is reduced. An optimized EGR system should lead to better performance values in a region between maximum power and maximum efficiency values.

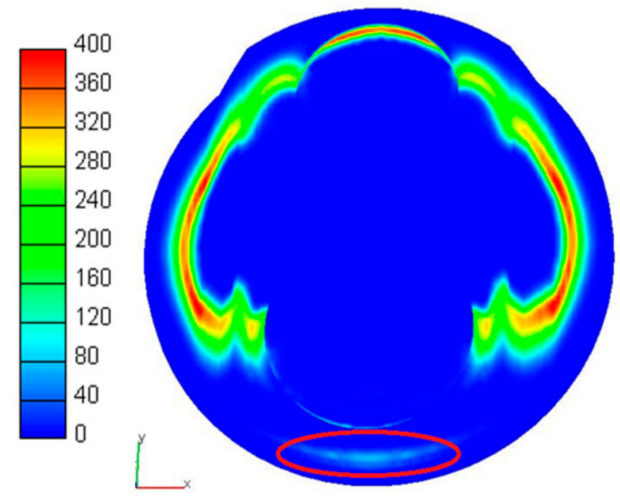

(a)

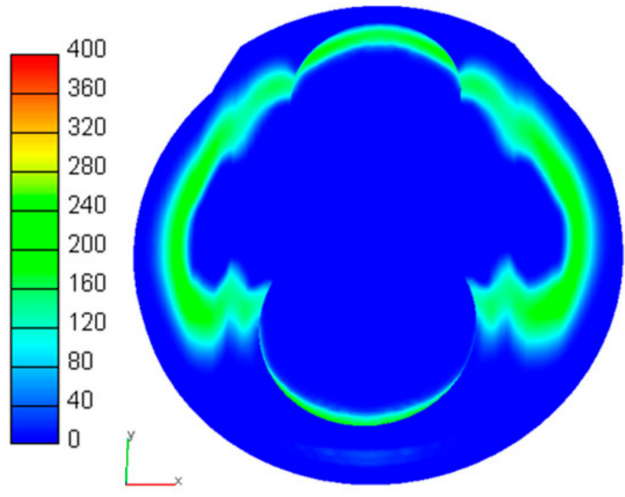

(b)

Figure 11. Comparison of reaction rates $\left(\mathrm{kg} / \mathrm{m}^{3} / \mathrm{s}\right)$ when flames travel at the same distance: (a) $1 \%$ EGR (TDC); (b) $10 \%$ EGR $\left(10^{\circ} \mathrm{CA}\right.$ aTDC).

\subsection{Effects of EGR System on Pre-ignition}

The pre-ignition of the hydrogen-fueled engine means that the mixed gas is burned before the spark plug is normally ignited. The high ignition point of hydrogen is suitable for the ignition, but the lower ignition energy is prone to premature combustion. Especially in the long-term high-speed operation with a high load and high compression ratio, the cylinder is prone to generate hot spots and ignite the in-cylinder mixture. As a result, pre-ignition happens. The pre-ignition of a hydrogen-fueled engine is mostly ignited by the high-temperature hot spots. The hot spots might be at the top of the spark plug or the throat of the exhaust valve seat or the small protrusion of the combustion chamber or the superheated impurity deposits or even the carbon deposit generated by the decomposition of the oil at a high temperature.

The pre-ignition condition of the K5A hydrogen-fueled engine in Figure 12 was measured at an engine speed of $2200 \mathrm{r} / \mathrm{min}$ and an ignition timing of $-29^{\circ} \mathrm{CA}$ aTDC, while the air/fuel ratio was $\lambda=1.2$. The condition of normal combustion in Figure 12 is under $2000 \mathrm{r} / \mathrm{min}$ engine speed and $\lambda=1.47$. The pre-ignition here is only a single working cycle and not an averaged simulation case, as it is typically calculated. After the pre-ignition cycle, the next working cycle is typically very different at a real engine. It can be seen from Figure 12 that the phase of the in-cylinder pressure occurs earlier than the normal combustion. When the pre-ignition occurs, the peak pressure rise rate occurs before the TDC, and the highest combustion pressure increase rate is almost three times that of the normal 
combustion. When the pre-ignition occurs, the phase of the in-cylinder pressure curve is earlier than the normal combustion, and the highest combustion pressure is almost twice the peak pressure during normal combustion. The area of the indicator of pre-ignition is larger than the area of the normal combustion, but the overall combustion curve for both the pre-ignition and the normal combustion is located before the TDC, making the compression of the piston is very large, which is not conducive to improving the hydrogen-fueled engine's power. The peak in-cylinder combustion pressure and pressure increase rate during the pre-ignition are much larger than those for the normal combustion and the combustion volume is too large. Moreover, the friction loss and the heat transfer loss increase as the compression negative work increases, decreasing the thermal efficiency and the power of the hydrogen-fueled engine. The earlier the pre-ignition occurs, the greater the rate of increase in the pressure and the more serious the engine power loss. Besides, the pre-ignition under the rich mixture would be more serious.

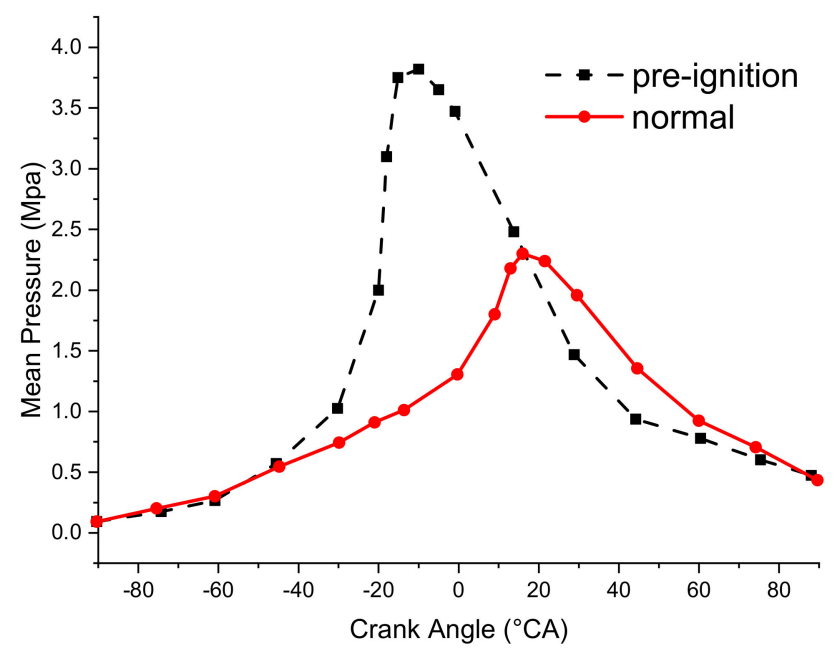

Figure 12. The pressure comparison for the normal combustion and the pre-ignition.

When the hydrogen-fueled engine is pre-ignited, the hot surface heats the mixture for a long time in the intake and the compression strokes, making the in-cylinder temperature and the pressure higher than those in the normal combustion. In addition, the fire area of the mixture is much larger than that when the spark plug is used alone due to the ignition of the hot spots. After ignition, the flame front quickly spreads throughout the combustion chamber and burns violently. When the early combustion of the hydrogen-fueled engine occurs, the combustion becomes unstable, the peak combustion pressure greatly fluctuates, and the in-cylinder pressure increase rate continuously increases. The pre-ignition causes tempering and stalls the engine. A significant feature of the pre-ignition of the hydrogen-fueled engine is the excessive in-cylinder pressure rise rate and the peak combustion pressure; both of them occur before the TDC. Moreover, the value of the pressure rise rate is a key factor in the study of the hydrogen engine pre-ignition. Furthermore, the excessive pressure rise rate values are more likely to trigger the generation of hot spots, which in turn leads to premature combustion. The EGR system controls the pressure increase rate, lowers the in-cylinder combustion temperature, and reduces the number of hot spots, hence, suppressing the occurrence of the pre-ignition in a hydrogen engine.

\subsection{Measures to Control Abnormal Combustion}

How to effectively reduce the rate of pressure rise becomes the focus of mitigating the early combustion of hydrogen internal combustion engines. Hydrogen injection timing and hydrogen injection pulse width, spark advance angle, fuel-air equivalent ratio, compression ratio, and EGR ratio are all important parameters for controlling the pressure increase rate. Combined with the results of the simulation study, the following measures can be taken to control the abnormal combustion of the hydrogen internal combustion engine: 
(1) The precise control of the EGR ratio is not only effective in reducing NOx emissions but also effectively suppresses pre-ignition and knocking. The control of EGR ratio, hydrogen injection timing, and hydrogen pulse width can be realized by advanced electronic control technology. For each working condition, the most accurate amount of hydrogen can be injected accurately, and the optimal exhaust gas circulation can be selected. To a large extent, it can mitigate the occurrence of abnormal combustion such as pre-ignition.

(2) Reducing the spark advance angle will reduce the rate of pressure rise, and the in-cylinder temperature and pressure will decrease accordingly. Then the possibility of pre-ignition and knocking decreases. However, too small a spark advance angle will make the power of hydrogen internal combustion engine worse, and post-combustion will lead to serious deterioration of thermal efficiency and emissions. Finding the best spark advance angle under different operating conditions is the focus of the research work.

(3) Pre-ignition is caused by the high compression ratio of the engine and the in-cylinder hotspot. Therefore, the engine should use a suitable compression ratio, strictly keep the cylinder clean, reduce spark plug clearance, and cooperate with the use of cooler spark plugs to enhance heat dissipation in special parts.

(4) Accurate electronic fuel injection technology can not only ensure the efficient operation of the engine but also suppress the abnormal combustion of the hydrogen engine. By using the EFI system, part of the air can enter the cylinder first. After cooling the combustion chamber, a mixture is formed, which can be cooled again where the inlet valve seat and piston head are overheated. Such an engine not only has an excess air coefficient but also improves the output power and combustion efficiency.

\section{Conclusions}

In this work, a 3D CFD prediction model of a K5A hydrogen-fueled internal combustion engine was established. The simulation of the flame propagation and the in-cylinder flow field was carried out. The effects of EGR system on the combustion characteristics and the abnormal combustion of the hydrogen-fueled engine were studied. The main conclusions are listed as follows.

(1) The peak in-cylinder pressure continuously increased with the increase of the spark advance angle and was closer to the TDC. The earlier the spark timing, the lower the average temperature in the cylinder when the exhaust valve opens. Looking for an optimal spark advance was the key to improving the performance of the hydrogen-fueled engine. Moreover, the air/fuel ratio $\lambda$ greatly influenced the combustion process of the hydrogen-fueled engine. The combustion of the mixture near the theoretical air/fuel ratio was more severe, which shortened the combustion duration.

(2) Increasing the EGR ratio decreased the peak in-cylinder pressure, the average temperature, and the NOx emissions. Decreasing the high-temperature zones was the main cause of the reduction in NOx emissions from the hydrogen-fueled engine. Low-temperature combustion delayed the spontaneous combustion reaction of the end mixture and effectively reduced the probability of hydrogen engine knocking. The increase of the EGR ratio increased the combustion duration and the peak heat release rate, and the overall combustion phase shifted backward.

(3) The remarkable characteristics of the early combustion of hydrogen-fueled engines were the excessive in-cylinder pressure increase rate and the maximum combustion pressure, both of which occurred before TDC. The EGR system controlled the pressure increase rate and reduced the in-cylinder hot spots, thereby suppressing the occurrence of pre-ignition of the hydrogen engine.

(4) CFD simulation can be a powerful tool for hydrogen engines design. In the future research work, many technologies such as further optimized low-temperature combustion strategy, accurate electronic fuel injection control, appropriate EGR cooler, and optimized ignition timing can be used together to suppress the knocking of hydrogen engines.

Author Contributions: H.G. and S.Z. contributed to the case study and the original manuscript.; J.Z. checked the results of the whole manuscript; M.S. translated the original manuscript. All authors have read and agreed to the published version of the manuscript. 
Funding: This research was supported by the China financial support of Marine Low-Speed Engine Project-Phase I, grant number MC-201501-D01-03.

Acknowledgments: This research is supported by the AVL-FIRE Engine Simulation Software from AVL LIST. Great thanks for valuable comments and suggestions of the reviews and the editors of MDPI.

Conflicts of Interest: The authors declare no conflict of interest.

$\begin{array}{ll}\text { Abbreviations } \\ \mathrm{P} & \text { Cylinder Pressure } \\ \mathrm{CFD} & \text { Computational Fluid Dynamics } \\ \mathrm{LTC} & \text { Low Temperature Combustion } \\ \text { 3D } & \text { Three-Dimensional } \\ \mathrm{PFI} & \text { Port Fuel Injection } \\ \mathrm{EFI} & \text { Electronic Fuel Injection } \\ \lambda & \text { Air-Fuel Ratio } \\ \mathrm{CO}_{2} & \text { Carbon Dioxide } \\ \mathrm{CO} & \text { Carbon Monoxide } \\ \mathrm{H}_{2} \mathrm{O} & \text { Hydrogen Dioxide } \\ \mathrm{MBT} & \text { Maximum Brake Torque } \\ \mathrm{CH} & \text { Methane } \\ \mathrm{NOx} & \text { Nitrogen Oxides } \\ \mathrm{NO} & \text { Nitro Oxide } \\ \mathrm{CAD} & \text { Computer Aided Design } \\ \mathrm{ROHR} & \text { Rate of Heat Release } \\ \text { TDC } & \text { Top Dead Center } \\ { }^{\circ} \mathrm{CA} & \text { Crank Angle Degree } \\ \text { bTDC } & \text { Before Top Dead Center } \\ \text { aTDC } & \text { After Top Dead Center }\end{array}$

\section{References}

1. Xiang, L.; Theotokatos, G.; Cui, H.; Xu, K.; Ben, H.; Ding, Y. Parametric knocking performance investigation of spark ignition natural gas engines and dual fuel engines. J. Mar. Sci. Eng. 2020, 8, 459. [CrossRef]

2. Guo, H.; Zhou, S.; Shreka, M.; Feng, Y. Effect of pre-combustion chamber nozzle parameters on the performance of a marine 2-stroke dual fuel engine. Processes 2019, 42, 876. [CrossRef]

3. Gao, J.; Tian, G.; Sorniotti, A.; Karci, A.E.; di Palo, R. Review of thermal management of catalytic converters to decrease engine emissions during cold start and warm up. Appl. Therm. Eng. 2019, 147, 177-187. [CrossRef]

4. Duan, X.; Lai, M.C.; Jansons, M.; Guo, G. A review of controlling strategies of the ignition timing and combustion phase in homogeneous charge compression ignition (HCCI) engine. Fuel 2021, 285, 119142. [CrossRef]

5. Apak, S.; Atay, E.; Tuncer, G. Renewable hydrogen energy and energy efficiency in Turkey in the 21st century. Int. J. Hydrog. Energy 2017, 42, 2446-2452. [CrossRef]

6. Verhelst, S. Recent progress in the use of hydrogen as a fuel for internal combustion engines. Int. J. Hydrog. Energy 2014, 39, 1071-1085. [CrossRef]

7. Zhou, J.H.; Cheung, C.S.; Zhao, W.Z.; Leung, C.W. Diesel hydrogen dual-fuel combustion and its impact on unregulated gaseous emissions and particulate emissions under different engine loads and engine speeds. Energy 2016, 94, 110-123. [CrossRef]

8. Yadav, V.S.; Soni, S.L.; Sharma, D. Engine performance of optimized hydrogen-fueled direct injection engine. Energy 2014, 65, 116-122. [CrossRef]

9. Jabbr, A.I.; Vaz, W.S.; Khairallah, H.A.; Koylu, U.O. Multi-objective optimization of operating parameters for hydrogen-fueled spark-ignition engines. Int. J. Hydrog. Energy 2016, 41, 18291-18299. [CrossRef]

10. Dong, J. Impact of Reformed Ethanol on the Volumetric Efficiency in I.C. Engines; SAE: Wallendale, PA, USA, 2010.

11. Ingenito, A.; Agresta, A.; Andriani, R.; Gamma, F. NOx reduction strategies for high speed hydrogen fuelled vehicles. Int. J. Hydrog. Energy 2015, 40, 5186-5196. [CrossRef] 
12. Heffel, J. NOx emission reduction in a hydrogen fueled internal combustion engine at $3000 \mathrm{r} / \mathrm{min}$ using exhaust gas recirculation. Int. J. Hydrog. Energy 2003, 28, 1285-1292. [CrossRef]

13. Chaichan, M.T. EGR effects on hydrogen engines performance and emissions. Int. J. Sci. Eng. Res. 2016, 7, $80-90$.

14. Kunal, R.; Natarajan, S.; Das, L.M. Effects of Governing Parameters on the Performance and Emissions of Hydrogen Engine for Automotive Application; SAE Technical Paper 2013-01-2891; SAE: Wallendale, PA, USA, 2013.

15. Yadav, V.S.; Sharma, D.; Soni, S.L. Performance and combustion analysis of hydrogen-fuelled C.I. engine with EGR. Int. J. Hydrog. Energy 2015, 40, 4382-4391. [CrossRef]

16. Subramanian, V.; Mallikarjuna, J.M.; Ramesh, A. Effect of water injection and spark timing on the nitric oxide emission and combustion parameters of a hydrogen fuelled spark ignition engine. Int. J. Hydrog. Energy 2007, 1159-1173. [CrossRef]

17. Sierens, R.; Verhelst, S.; Verstraeten, S. EGR and lean combustion strategies for a single cylinder hydrogen fuelled IC engine. In Proceedings of the 2005 EAEC European Automotive Congress, Beograd, Serbia, 30 May-1 June 2005.

18. Abhijeet, M.N.; Stanislaw, S. Impact of EGR on Combustion Processes in a Hydrogen Fuelled SI Engine; SAE Technical Paper 2008-01-1039; SAE: Wallendale, PA, USA, 2008.

19. Safari, H.S.A.; Jazayeri, R.E. Potentials of NOx emission reduction methods in SI hydrogen engines-simulation study. Int. J. Hydrog. Energy 2009, 34, 1-11. [CrossRef]

20. Yang, Z.; Wang, L.; Li, J. Research on the optimizing control technology based on fuzzy-neural network for hydrogen fueled engines. Int. J. Hydrog. Energy 2006, 31, 2370-2377. [CrossRef]

21. Yang, Z.; Zhang, F.; Wang, L. Effects of injection mode on the mixture formation and combustion performance of the hydrogen internal combustion engine. Energy 2018, 147, 715-728. [CrossRef]

22. Lee, J.; Lee, K.; Lee, J.; Anh, B. High power performance with zero NOx emission in a hydrogen-fueled spark ignition engine by valve timing and lean boosting. Fuel 2014, 128, 381-389. [CrossRef]

23. Luo, Q.; Sun, B. Inducing factors and frequency of combustion knock in hydrogen internal combustion engines. Int. J. Hydrog. Energy 2016, 41, 16296-16305. [CrossRef]

24. Ji, C.; Yang, J.; Liu, X.; Wang, S.; Zhang, B.; Wang, D. Enhancing the fuel economy and emissions performance of a gasoline engine-powered vehicle with idle elimination and hydrogen start. Apply Energy 2016, 182, 135-144. [CrossRef]

25. Dharamshi, K.; Srivastava, D.K.; Agarwal, A.K. Combustion characteristics and flame-kernel development of a laser ignited hydrogen air mixture in a constant volume combustion chamber. Int. J. Hydrog. Energy 2014, 39, 593-601. [CrossRef]

26. Sun, Z.Y.; Li, G.X. Propagation characteristics of laminar spherical flames within homogeneous hydrogen-air mixtures. Energy 2016, 116, 116-127. [CrossRef]

27. Duan, X.; Wang, H.K.; Li, Y.; Guo, H.; Liu, J. Numerical simulation the effect of hydrogen addition on the flame propagation and emissions formation in a large-bore lean-burn natural gas SI engine. Energy 2020, 9 , 62.

28. Duan, X.; Zhang, S.; Liu, Y.; Li, Y.; Liu, J.; Lai, M.-C.; Deng, B. Numerical investigation the effects of the twin-spark plugs coupled with EGR on the combustion process and emissions characteristics in a lean burn natural gas SI engine. Energy 2020, 206, 118181. [CrossRef]

29. Nemati, A. Numerical investigation of the effect of injection timing under various equivalence ratios on energy and exergy terms in a direct injection SI hydrogen fueled engine. Int. J. Hydrog. Energy 2012, 38, 1189-1199. [CrossRef]

(C) 2020 by the authors. Licensee MDPI, Basel, Switzerland. This article is an open access article distributed under the terms and conditions of the Creative Commons Attribution (CC BY) license (http://creativecommons.org/licenses/by/4.0/). 